\title{
Effects of core balance training on Cobb angle, isokinetic torque, and balance in unilateral handed athletes
}

\author{
Sung-Hwan Bang ${ }^{1}$, Jang-Gun Yoon', Jeong-Min Park ${ }^{2, *}$ \\ 'Department of Special Warfare Medical Non-Commissioned Officer, Daejeon Health Institute of Technology, Daejeon, Korea \\ ${ }^{2}$ Department of Physical Education, Chungnam National University, Daejeon, Korea
}

This study aimed to provide fundamental data of core balance training (CBT) on Cobb angle and isokinetic torque and balance in unilateral exercised athletes. Forty-eight subjects were divided by control group (CON; $n=16)$, non-CBT exercised group in unilateral handed athletes (NEG, $n=16)$, and CBT exercised group in unilateral handed athletes $(E G, n=16)$, respectively. Although the group by time interaction in the Cobb angle and in the isokinetic torque were not significantly changed in the EG, the balance of the EG showed significantly improved. As conclusions, these results informed that the 16-week CBT would provide a positive effect on the balance except for the Cobb angle and the isokinetic torque.

Keywords: Core balance training, Cobb angle, Isokinetic torque, Balance, Unilateral handed athletes

\section{INTRODUCTION}

In all sports, various motions are completed based on the coordination between the professional physical strength and skills required by each sport. The practiced motion has a pattern of movement that is unique to each sport, through response, adaptation and application. The athletes conduct training that increases the completeness of the main motion patterns by analyzing the patterns of majored motions and muscle activities that will be determinants of professional physical strength and performance (Suchomel et al., 2018). A consistent pattern adapted through repetitive training enables athletes to respond to various situations in competitions to provide the best athletic performance through the adjustment of many muscles and joints during unpredictable sports. In order to improve the athletes' physical strength and specific skills, highintensity training, continuous training, and repetitive participation in competitions are essential. For athletes who have to perform in high-intensity sports, to do incorrect exercise habits, and to exercise a unilateral side may result in loss of physical balance, thus leading to decrease in competitiveness (Vikne et al., 2007).
Unilateral exercises include sports that are extremely biased to using one side of the body or sports that do not use the both the left and right sides equally, depending on the sports characteristics (Maloney, 2019). Specifically, unilateral exercise can lead to body asymmetry or body imbalance. Body imbalance can cause sports injury and damage. This imbalance, also referred to as "malalignment syndrome," is a symptom of the body's rearrangement from head to toe due to poor posture, including pelvic anteversion and changes in the alignment of the axial skeleton and the appendicular skeleton (Wilson, 2007). The malalignment of the body caused by incorrect postural management causes spinal deformity and progresses to abnormal spinal arrangements, resulting in not only poor appearance (Hawes and O'brien, 2006; Rhim et al., 2003), but also impaired physical activity accompanied by pain and stiffness. This can cause many limitations and discomfort in daily activities. It was reported that continuous unilateral exercises lead to changes in the muscles around the shoulder joints and spinal deformity (Van Gelein Vitringa et al., 2011).

Spinal deformity is majorly classified as lordosis, kyphosis, and scoliosis. Exercise-related spinal deformities include not only sco-
${ }^{*}$ Corresponding author: Jeong-Min Park (ib https://orcid.org/0000-0003-0547-3037 Department of Physical Education, Chungnam National University, 99 Daehak-ro, Yuseong-gu, Daejeon 34134, Korea

E-mail:mine7728@hanmail.net

Received: April 1, 2020 / Accepted: April 25, 2020
This is an Open Access article distributed under the terms of the Creative Commons Attribution Non-Commercial License (https://creativecommons.org/licenses/by-nc/4.0/) which permits unrestricted non-commercial use, distribution, and reproduction in any medium, provided the original work is properly cited. 
liosis, but also spinal dysraphism, decreased distance between intervertebral disks, abnormal epiphyseal plates in the spine, and Schmorl's nodes (Hellström et al., 1990). Scoliosis, the main spinal deformity, refers to a curvature greater than Cobb angle, or $10^{\circ}$ or more (Green et al., 2009). Here, this is defined as the left-right curvature of the spine with respect to the lateral movement of the spine on the sagittal plane and the torsion of the thorax (Edmondston et al., 2007). This scoliosis accompanies not only lateral deviation of the spine, but also rotational deformity. This results in abnormal morphology of the trunk and thorax, changes in the location of the head, shoulders, and pelvis, thus ultimately also affecting the balance. It has been reported that strengthening the muscles around the spine and performing pelvic muscle strengthening exercise can not only prevent but also correct spinal deformity and that balance can also be improved (Jeon and Kim, 2016). They also reported that better balance is known to have a positive effect on posture management. Furthermore, balance can predict many injuries that can result from sports, and its impact varies depending on the sports. Previous research studies have also reported that athletes' stability of balance can vary depending on the type of sports (Hrysomallis et al., 2007; McGuine, 2000; Willems et al., 2005).

As shown above, most of the various studies related to the spinal deformity due to the body imbalance focused on scoliosis, its causes, and treatment methods. However, research involving reviews of body alignment and balance of athletes is lacking. Moreover, most of the previous studies on balance are for preventing ankle injuries and falls of the elderly (McGuine, 2000). Even studies on athletes are mostly simple research on the effect of repetitive training and unilateral exercise on posture or the application of exercise programs to prevent injury (Holm et al., 2004). Research on the intervention on spinal deformity due to unilateral exercise or research that compares the effect of exercise methods or forms is very insufficient with a lack of evidence.

Therefore, the aim of this study was to investigate the effects of core balance training (CBT) using sling exercise and Kendall exercise on the Cobb angle, isokinetic torque, and balance of players who engage in unilateral exercises. The hypotheses of this study were as follows: CBT would (a) improve Cobb angle, (b) develop trunk muscles, and (c) increase balance in athletes who perform unilateral exercises.

\section{MATERIALS AND METHODS}

\section{Subjects}

The study sample consisted of 48 male adults who were mem-
Table 1. Demographic data of the participants

\begin{tabular}{|c|c|c|c|c|}
\hline \multirow{2}{*}{ Variable } & \multicolumn{3}{|c|}{ Groups } & \multirow{2}{*}{$F(P$-value $)$} \\
\hline & $\operatorname{CON}(n=16)$ & NEG $(n=16)$ & $E G(n=16)$ & \\
\hline Age (yr) & $20.94 \pm 1.61$ & $21.00 \pm 1.24$ & $20.37 \pm 1.84$ & $0.368(0.776)$ \\
\hline Height (cm) & $184.89 \pm 6.03$ & $182.46 \pm 5.04$ & $182.19 \pm 4.45$ & 0.458 (0.682) \\
\hline Weight (kg) & $82.74 \pm 4.90$ & $79.70 \pm 6.21$ & $77.09 \pm 3.49$ & $0.472(0.621)$ \\
\hline $\begin{array}{l}\text { Body mass index } \\
\left(\mathrm{kg} / \mathrm{m}^{2}\right)\end{array}$ & $26.06 \pm 2.46$ & $26.64 \pm 2.14$ & $25.34 \pm 2.41$ & $0.775(0.412)$ \\
\hline Cobb angle $\left({ }^{\circ}\right)$ & $10.66 \pm 4.02$ & $15.62 \pm 2.69$ & $16.44 \pm 3.51$ & $1.844(0.033)$ \\
\hline Carrier (yr) & $7.97 \pm 2.42$ & $8.24 \pm 2.68$ & $8.16 \pm 3.21$ & 0.364 (0.688) \\
\hline
\end{tabular}

Values are presented as mean \pm standard deviation.

CON, control group; NEG, nonexercise group; EG, exercise group.

bers in an elite team. Participants who engaged in unilateral exercises in this study were bowling players $(n=9)$, tennis players $(\mathrm{n}=9)$, and handball players $(\mathrm{n}=14)$, while participants who took part in both handed exercises were athletic players. Each of them did not perform unilateral exercise (athletic players) as a control group (CON, $n=16$ ), and athletes performing unilateral exercise as the experimental group. The experimental group was again divided into those who participated in core balance training (EG, $\mathrm{n}=16)$ and those who did not (NEG, $\mathrm{n}=16)$. The players who participated in NEG were bowling players $(n=4)$, tennis players $(n=6)$, and handball players $(n=6)$, while players participated in core balance training were bowling players $(n=5)$, tennis player $(\mathrm{n}=3)$, and handball player $(\mathrm{n}=8)$. Their careers were as shown in Table 1.

\section{Experimental design}

This study was conducted from March to December 2019 on unilateral exercised athletes who took part in CBT program and those who did not. Before conducting this study, the researchers obtained preapproval for this study from the Institutional Review Board of the Daejeon Health Institute of Technology (approval number: 1041490-201805-HR-020).

\section{Measurement method}

\section{$X$-ray measures}

$\mathrm{X}$-rays (DDR Inventor-V, Bucheon, Korea) were taken by a professional radiologist at a specialized medical institution. The participant straightened their back and chest, held their legs together neatly, and placed weight on both feet equally. Whole spine $\mathrm{X}$-rays were taken from the pelvis to the neck. Cobb angle was measured using Cobb method. The end vertebrae that were the most tilted toward the concave side of the curvature to be measured were determined at the upper and lower ends of the curvature. One 
line was drawn above the upper end of the vertebra, and the other line was drawn below the lower end of the vertebra. A line was drawn perpendicular to each line, and the angle in which the lines meet was obtained (Korean Medical Article Database, 2009). Cobb angle was measured by a specialist in rehabilitation medicine.

\section{Spinal movement measures}

Exbody musculoskeletal system diagnostic equipment (Clinical Gait Analysis 6100RMT, Seoul, Korea) was used to test for spinal movement. To maintain safety during measurement, treadmill equipment with supporting handles of $92 \mathrm{~cm}$ in height attached to a base of $96 \mathrm{~cm} \times 140 \mathrm{~cm}$ was used. The participant walked at a regular walking speed on a treadmill belt of size $62 \mathrm{~cm} \times 136 \mathrm{~cm}$ and measurements were taken for $10 \mathrm{~min}$. Only the knee motion values were used for the area of measurement. For measurement value, only the mean value of the middle was used after excluding the $30 \%$ at the beginning and end.

\section{Isokinetic torque measure}

An isokinetic dynamometer (HUMAC/NORM Testing \& Rehabilitation System, Computer Sports Medicine Inc., Stoughton, MA, USA) was used for this study. All subjects took part in a warm-up stretching before the real test. Subjects were placed on the trunk extension/flexion modular component in a standing position (Verbrugghe et al., 2019). In accordance with Testing User's Guide, the isokinetic torques of trunk extensor and flexor were measured in terms of concentric/concentric contraction mode at the angle-speed of $60^{\circ} / \mathrm{sec}$ and $180^{\circ} / \mathrm{sec}$. The rest time between measures was $60 \mathrm{sec}$. The trunk was secured at three points (waist, back, and shoulder) and the participant was instructed to hold the handles attached near the chest with both hands. Because the simultaneous contraction of the trunk in response to unexpected load can cause pain by leading to pressure and shearing force to the spine, the range of motion was set from extended $5^{\circ}$ to flexed $80^{\circ}$ to minimize the risk of injury. Subjects then performed four maximal warm-up repetitions and five maximal test repetitions at $60 \%$ sec and four maximal warm-up repetitions and 15 maximal test repetitions at $180^{\circ} / \mathrm{sec}$.

\section{Balance measure}

We used the HUMAC Balance System (Computer Sports Medicine Inc.) for static balance ability (Kim et al., 2015). The balance abilities gained as follow's tests in detail. This test of sensory organization and balance is used to test how a participant's vision, vestibular, and somatosensory systems interact. It is sometimes re- ferred to as the Romberg of Foam and Dome test. When the test started, the subject afforded to stand on the force plate by both legs for as long as possible with eyes opened. The mean time scores of three attempt were recorded.

\section{Core balance training program}

The CBT program was conducted for $60 \mathrm{~min}$ a day 3 days/a week for 16 weeks. The first exercise, sling exercise, was conducted in 30-min sessions per week based on Neurac's treatment method. Exercise methods included core cervical spine flexor strengthening (Buyukturan et al., 2017), scapula retractor strengthening (Fennell et al., 2016), and scapular protractor strengthening (Cools et al., 2005). Based on Kendall exercise method, this also was performed in 30-min sessions per week for 16 weeks. Exercise methods included core cervical spine flexor strengthening (Diab and Moustafa, 2012; Harman et al., 2005), scapular protractor strengthening (Cools et al., 2005), and scapula retractor strengthening (Boettcher et al., 2009; Fleming et al., 2010; Tino and Hillis, 2010). The subjects conducted 60-min sessions per week for 16 weeks. The exercise program consisted of a total of three stages. The goal of the CBT was to obtain basic balance and muscle strengthening for first 4 weeks; the another goal was to make a balancing ability and to enhance an active muscle strengthening for next 4 weeks; the last goal of CBT in this study was to perform a dynamic balancing and strengthen in the trunk for more 4 weeks. The CBT program conducted in this study is as shown in Table 2.

\section{Statistical analysis}

A total of 48 participants were selected for this study. The necessary sample size was calculated to be 48 using $\mathrm{G}^{*}$ power 3.1.9.4 program (three groups, effect size $=0.3$, significance level $\alpha=0.05$, power $1-\beta=0.80$ ). All data measured for this study were processed using IBM SPSS Statistics ver. 20.0 (IBM Co., Armonk, NY, USA). Means and standard deviations of spine-related motions and pain

Table 2. Core balance training program for exercise group

\begin{tabular}{cccccc}
\hline Stage & $\begin{array}{c}\text { Time } \\
\text { (min) }\end{array}$ & $\begin{array}{c}\text { Repetitions/ } \\
\text { sets }\end{array}$ & $\begin{array}{c}\text { Intensity } \\
\text { (RPE) }\end{array}$ & $\begin{array}{c}\text { Period } \\
\text { (wk) }\end{array}$ & Core balance training \\
\hline 1 & 40 & $10 / 3$ & $8-10$ & $1-5$ & Sling exercise (Low tension, pull \\
2 & 40 & $10 / 5$ & $11-12$ & $6-11$ & $\begin{array}{l}\text { up, row, push up, fly, roll out, } \\
\text { bridge, leg curl, plank, } \\
\text { abdominal curl) } \\
\text { Kendall exercise (deep cervical } \\
\text { flexion, shoulder protraction, } \\
\text { shoulder retraction) }\end{array}$ \\
\hline
\end{tabular}

RPE, ratings of perceived exertion. 
Table 3. Changes of Cobb angle and spinal movement levels

\begin{tabular}{|c|c|c|c|c|c|c|c|}
\hline \multirow{2}{*}{ Item } & \multirow{2}{*}{ Time $(T)$} & \multicolumn{3}{|c|}{ Groups (G) } & \multicolumn{3}{|c|}{$F$} \\
\hline & & CON & NEG & $\mathrm{EG}$ & G & $\mathrm{T}$ & $G \times T$ \\
\hline \multirow[t]{2}{*}{ Cobb angle $\left({ }^{\circ}\right)$} & Pre & $10.66 \pm 4.02$ & $15.62 \pm 2.69$ & $16.44 \pm 3.51$ & $6.539 * *$ & 0.876 & 1.243 \\
\hline & Post & $9.87 \pm 2.03$ & $15.72 \pm 3.02$ & $15.98 \pm 2.64$ & & & \\
\hline \multirow[t]{2}{*}{ Spinal movement left/right $\left({ }^{\circ}\right)$} & Pre & $30.66 \pm 3.32$ & $24.62 \pm 1.84$ & $23.96 \pm 2.28$ & $51.165^{* * *}$ & $12.748^{* * *}$ & 0.541 \\
\hline & Post & $28.98 \pm 4.36$ & $25.54 \pm 5.24$ & $33.64 \pm 2.78$ & & & \\
\hline \multirow[t]{2}{*}{ Spinal movement up/down $\left({ }^{\circ}\right)$} & Pre & $36.91 \pm 1.73$ & $36.16 \pm 2.69$ & $36.25 \pm 2.48$ & 0.209 & $12.271^{* * *}$ & 0.770 \\
\hline & Post & $35.49 \pm 5.01$ & $33.68 \pm 5.43$ & $43.05 \pm 4.80$ & & & \\
\hline
\end{tabular}

Values are presented as mean \pm standard deviation.

$\mathrm{CON}$, control group; NEG, nonexercise group; EG, exercise group.

Symbols ** and ${ }^{* * *}$ mean significance in the $\mathrm{T}, \mathrm{G}$, and $\mathrm{G} \times \mathrm{T}$.

${ }^{* *} P<0.01 .{ }^{* * *} P<0.001$.

Table 4. Changes of isokinetic peal torque (PT) of trunk

\begin{tabular}{|c|c|c|c|c|c|c|c|}
\hline \multirow{2}{*}{ Item } & \multirow{2}{*}{ Time (T) } & \multicolumn{3}{|c|}{ Groups (G) } & \multicolumn{3}{|c|}{$F$} \\
\hline & & CON & NEG & EG & G & $\mathrm{T}$ & $G \times T$ \\
\hline \multirow[t]{2}{*}{ Extensor PT (Nm) } & Pre & $276.42 \pm 85.95$ & $287.42 \pm 50.55$ & $280.36 \pm 62.02$ & 0.065 & $9.876^{* * *}$ & 0.224 \\
\hline & Post & $282.92 \pm 56.48$ & $283.36 \pm 40.57$ & $301.47 \pm 43.81$ & & & \\
\hline \multirow[t]{2}{*}{ Flexor PT (Nm) } & Pre & $175.75 \pm 36.97$ & $184.83 \pm 24.35$ & $180.94 \pm 30.84$ & 0.938 & $11.240^{* * *}$ & 0.701 \\
\hline & Post & $178.33 \pm 29.06$ & $186.66 \pm 22.56$ & $190.20 \pm 23.93$ & & & \\
\hline
\end{tabular}

Values are presented as mean \pm standard deviation.

CON, control group; NEG, nonexercise group; EG, exercise group.

Symbols ** and ${ }^{* * *}$ mean significance in the $\mathrm{T}, \mathrm{G}$, and $\mathrm{G} \times \mathrm{T}$.

${ }^{* *} P<0.01 .{ }^{* *} P<0.001$.

variables were calculated. Then, two-way repeated-measures analysis of variance (ANOVA) was performed to test the significance between 2 times (pretest and posttest) and among three groups. After the ANOVA, significance testing between pretest and posttest within each group and significance testing among the groups were performed with comparative analyses using Syntax. Here, statistical significance was set to $\alpha=0.05$.

\section{RESULTS}

\section{Changes in Cobb angle and spinal motion after core balance training}

Table 3 summarizes the changes observed in the Cobb angles. Significant group $\times$ time interaction effects were not observed for Cobb angle, spinal motion by left/right sides, and spinal motion by up/down sides, respectively. Precisely, there was a decreasing tendency observed in the Cobb angle in the EG that was greater than the changes observed in the NEG. On the other hand, the spinal motion by left/right sides and spinal motion by up/down sides in the EG showed significantly changed in times compared to the changes in the CON and the NEG.

\section{Changes in isokinetic torques after core balance training}

Table 4 summarizes the changes observed in the isokinetic torques. Significant group $\times$ time interaction effects were not observed for isokinetic torques of trunk. Concisely, there was no changes in the CON and NEG, whereas the trunk extensor and flexor in the EG were significantly changed in times.

\section{Changes in balance after core balance training}

Table 5 summarizes the changes observed in the balance. Significant group $\times$ time interaction effects were observed for balances in all four-wards. Concisely, there were no changes or small increases in the CON and NEG, whereas the balances of up-, down-, left-, and right-wards in the EG were significantly changed in times and in group $\times$ time interaction effects.

\section{DISCUSSION}

This study aims to discuss the following based on the results of analyzing the effect of CBT on Cobb's angle, isokinetic muscle torque, and balance in athletes who have engaged in unilateral exercises. This study found some significant changes after 16-week 
Table 5. Changes of balance levels

\begin{tabular}{|c|c|c|c|c|c|c|c|}
\hline \multirow{2}{*}{ Item } & \multirow{2}{*}{ Time (T) } & \multicolumn{3}{|c|}{ Groups (G) } & \multicolumn{3}{|c|}{$F$} \\
\hline & & CON & NEG & EG & G & $T$ & $\mathrm{G} \times \mathrm{T}$ \\
\hline \multirow[t]{2}{*}{ Up } & Pre & $43.16 \pm 10.55$ & $42.12 \pm 10.69$ & $44.88 \pm 11.74$ & 2.012 & $8.693^{* *}$ & $6.283^{*}$ \\
\hline & Post & $44.86 \pm 6.59$ & $43.02 \pm 9.84$ & $49.83 \pm 7.59$ & & & \\
\hline \multirow[t]{2}{*}{ Down } & Pre & $42.50 \pm 17.92$ & $41.00 \pm 20.00$ & $40.27 \pm 19.86$ & 0.882 & $9.886^{* *}$ & $6.887^{*}$ \\
\hline & Post & $43.26 \pm 8.78$ & $40.83 \pm 9.67$ & $49.11 \pm 9.30$ & & & \\
\hline \multirow[t]{2}{*}{ Left } & Pre & $39.33 \pm 15.42$ & $36.50 \pm 13.56$ & $38.67 \pm 13.88$ & 0.209 & $10.171^{* *}$ & $8.770^{*}$ \\
\hline & Post & $39.91 \pm 9.51$ & $38.64 \pm 9.00$ & $50.22 \pm 8.89$ & & & \\
\hline \multirow[t]{2}{*}{ Right } & Pre & $43.84 \pm 12.86$ & $46.36 \pm 10.83$ & $47.13 \pm 11.37$ & 1.230 & $6.036^{*}$ & $4.549^{*}$ \\
\hline & Post & $44.83 \pm 11.19$ & $44.50 \pm 7.57$ & $50.05 \pm 9.33$ & & & \\
\hline
\end{tabular}

Values are presented as mean \pm standard deviation.

$\mathrm{CON}$, control group; NEG, nonexercise group; EG, exercise group.

Symbols * and ** mean significance in the T, G, and $\mathrm{G} \times \mathrm{T}$.

${ }^{*} P<0.05$. ${ }^{* *} P<0.01$.

CBT program. In other words, there were no significant changes in the group $\times$ time interaction effects for Cobb angle, spinal motion by left/right sides, and spinal motion by up/down sides. Moreover, although the trunk extensor and flexor in the EG were significantly changed in times, the significant group $\times$ time interaction effects for isokinetic torques of trunk were not observed. However, significant group $\times$ time interaction effects were observed for balances in all four-wards. In other words, there were no changes or small increases in the CON and NEG, whereas the four-wards' balances in the EG were significantly changed.

Vertebral joint is a structure that is responsible for important functions in human body. Maintaining healthy conditions in physical, mental, and social life are considered important from the past to the present (Dysvik et al., 2010). However, malalignment of the body due to inappropriate postural management leads to spinal deformities, and continuous unilateral exercises are reported to lead to changes in the muscles around the shoulder joints that can cause spinal deformities (Van Gelein Vitringa et al., 2011). These unilateral exercises decrease the competitiveness of the athletes and increase the risk of sports injury due to body imbalances and spinal deformity. These morphological and functional changes can hinder the continuation of an athlete career unilateral exercises cause spinal deformities, including not only the lateral deviation from the central axis but also complications such as cardiopulmonary dysfunction and backache (Xu et al., 2020). They can also move or pressure the surrounding organs to cause dysfunctions and decrease life expectancy. A main method to diagnose this spinal deformity is to assess Cobb angle and motion of the vertebral joint. In particular, changes in athletes with functional spinal deformities due to unilateral exercises help with kinetic interests (Pedersen et al.,
2015), but excessive deformities are judged to be a factor that reduces kinetic functions. Therefore, this study assessed the spinal joint deformities in athletes who engage in unilateral exercises through CBT that applied sling and Kendall exercises that are assessed to be spinal rehabilitation exercises. Although there were no statistically significant improvements in Cobb angle of the vertebral joint positive effects on the spinal motions were found after the exercises. These results were somewhat similar or somewhat different in the aspect of the problems of previous studies that assessed the functional motor skills of athletes engaging in unilateral and bilateral exercises (Eliassen et al., 2018). Benedetti et al. (2018) reported that the rehabilitation program of vertebral joint through equipment-based exercises might suggest a positive improvement. Summers et al. (2007) reported that the similar effect of bilateral and unilateral exercise on muscle functions in the athletes.

Spinal deformity due to unilateral exercise is reported to have greatly adverse effects on maintaining stable changes in the body balance and muscle function loss (Murphy and Carroll, 2003). In particular, the changes in the body shape and balance during the growth phase in youth are reported to have a large impact on the body's development (Pedersen et al., 2015). This is because growthoriented body development shows large health significances in the ideal improvement of muscle functions and the stabilization of body balance (Schoenfeld, 2010). Although this study found inadequate morphological changes and trunk musculatures of athletes who engage in unilateral exercise after CBT, the balance of this study showed the positive results found in previous studies (Nakai et al., 2019; van Dulmen et al., 1997). These findings are somewhat in line with researches that reported improvements in 
body balance and muscle functions and body alignment of the athletes who engage in unilateral exercises. These results also support previous research on the stabilization and body balance in hemiplegic patients (Bogataj et al., 1995).

As such, unilateral exercises bring forth many problems. In particular, many studies to prevent and treat the athletes with professional physical strength and sport-specific functional characteristics need to be conducted. Since this study found that Cobb angle was improved due to body imbalance in athletes who engage in unilateral exercises as well as isokinetic muscle function and balance from CBT, this can be used as important basic data for the prevention and management of athletes' injuries due to unilateral exercise and contribute to the development of exercise programs. Furthermore, the development of unilateral exercise improvement programs may athletes who want to become leaders in the field of education after their athletic careers.

However, the result of this study found a positive change only in the balance. Therefore, we may infer that the period of experiment was somewhat shorter and different volumes of intervention protocols than other previous studies. In other words, these results suggest that the CBT used in this study does not help spinal alignment, assuming that the subjects of this study are all adults and the spinal alignment has already deformed. Therefore, in order to investigate whether $\mathrm{CBT}$ can bring positive results to the spinal alignment, we think that it is possible to construct a long-term study period or to target the younger athletes who have participated in unilateral exercise.

\section{CONFLICT OF INTEREST}

No potential conflict of interest relevant to this article was reported.

\section{ACKNOWLEDGMENTS}

This study was supported by the Research Grant of Daejeon Health Institute of Technology in 2018.

\section{REFERENCES}

Benedetti MG, Furlini G, Zati A, Letizia Mauro G. The effectiveness of physical exercise on bone density in osteoporotic patients. Biomed Res Int 2018;2018:4840531.

Boettcher CE, Ginn KA, Cathers I. Which is the optimal exercise to strengthen supraspinatus? Med Sci Sports Exerc 2009;41:1979-1983.
Bogataj U, Gros N, Kljajić M, Aćimović R, Malezic M. The rehabilitation of gait in patients with hemiplegia: a comparison between conventional therapy and multichannel functional electrical stimulation therapy. Phys Ther 1995;75:490-502.

Buyukturan B, Guclu-Gunduz A, Buyukturan O, Dadali Y, Bilgin S, Kurt EE. Cervical stability training with and without core stability training for patients with cervical disc herniation: a randomized, single-blind study. Eur J Pain 2017;21:1678-1687.

Cools AM, Witvrouw EE, Mahieu NN, Danneels LA. Isokinetic scapular muscle performance in overhead athletes with and without impingement symptoms. J Athl Train 2005;40:104-110.

Diab AA, Moustafa IM. The efficacy of forward head correction on nerve root function and pain in cervical spondylotic radiculopathy: a randomized trial. Clin Rehabil 2012;26:351-361.

Dysvik E, Kvaløy JT, Stokkeland R, Natvig GK. The effectiveness of a multidisciplinary pain management programme managing chronic pain on pain perceptions, health-related quality of life and stages of changeA non-randomized controlled study. Int J Nurs Stud 2010;47:826-835.

Edmondston SJ, Aggerholm M, Elfving S, Flores N, Ng C, Smith R, Netto $\mathrm{K}$. Influence of posture on the range of axial rotation and coupled lateral flexion of the thoracic spine. J Manipulative Physiol Ther 2007;30: 193-199.

Eliassen W, Saeterbakken AH, van den Tillaar R. Comparison of bilateral and unilateral squat exercises on barbell kinematics and muscle activation. Int J Sports Phys Ther 2018;13:871-881.

Fennell J, Phadke CP, Mochizuki G, Ismail F, Boulias C. Shoulder retractor strengthening exercise to minimize rhomboid muscle activity and subacromial impingement. Physiother Can 2016;68:24-28.

Fleming JA, Seitz AL, Ebaugh DD. Exercise protocol for the treatment of rotator cuff impingement syndrome. J Athl Train 2010;45:483-485.

Green BN, Johnson C, Moreau W. Is physical activity contraindicated for individuals with scoliosis? A systematic literature review. J Chiropr Med 2009;8:25-37.

Harman K, Hubley-Kozey CL, Butler H. Effectiveness of an exercise program to improve forward head posture in normal adults: a randomized, controlled 10-week trial. J Man Manip Ther 2005;13:163-176.

Hawes MC, O'brien JP. The transformation of spinal curvature into spinal deformity: pathological processes and implications for treatment. Scoliosis 2006;1:3.

Hellström M, Jacobsson B, Swärd L, Peterson L. Radiologic abnormalities of the thoraco-lumbar spine in athletes. Acta Radiol 1990;31:127-132.

Holm I, Fosdahl MA, Friis A, Risberg MA, Myklebust G, Steen H. Effect of neuromuscular training on proprioception, balance, muscle strength, and lower limb function in female team handball players. Clin J Sport Med 2004;14:88-94. 
Hrysomallis C, McLaughlin P, Goodman C. Balance and injury in elite Australian footballers. Int J Sports Med 2007;28:844-847.

Jeon K, Kim S. Effect of unilateral exercise on spinal and pelvic deformities, and isokinetic trunk muscle strength. J Phys Ther Sci 2016;28:844-849.

Kim MH, Choi YT, Jee YS, Eun D, Ko IG, Kim SE, Yi ES, Yoo J. Reducing the frequency of wearing high-heeled shoes and increasing ankle strength can prevent ankle injury in women. Int J Clin Pract 2015;69: 909-910.

Korean Medical Article Database. Orthopaedic. Seoul (Korea): J Korean Orthop Assoc; 2009.

Maloney SJ. The relationship between asymmetry and athletic performance: a critical review. J Strength Cond Res 2019;33:2579-2593.

McGuine TA, Greene JJ, Best T, Leverson G. Balance as a predictor of ankle injuries in high school basketball players. Clin J Sport Med 2000;10:239244.

Murphy NM, Carroll P. The effect of physical activity and its interaction with nutrition on bone health. Proc Nutr Soc 2003;62:829-838.

Nakai Y, Kawada M, Miyazaki T, Kiyama R. Trunk muscle activity during trunk stabilizing exercise with isometric hip rotation using electromyography and ultrasound. J Electromyogr Kinesiol 2019;49:102357.

Pedersen BK, Saltin B. Exercise as medicine - evidence for prescribing exercise as therapy in 26 different chronic diseases. Scand J Med Sci Sports 2015;25 Suppl 3:1-72.

Rhim YT, Kim SS, Yoon SJ. The effects of exercise program on change in curve in girls with mild scoliosis. J Sport Stud 2003;19:1341-1347.

Schoenfeld BJ. The mechanisms of muscle hypertrophy and their application to resistance training. J Strength Cond Res 2010;24:2857-2872.

Suchomel TJ, Nimphius S, Bellon CR, Stone MH. The importance of muscular strength: training considerations. Sports Med 2018;48:765-785.

Summers JJ, Kagerer FA, Garry MI, Hiraga CY, Loftus A, Cauraugh JH. Bilateral and unilateral movement training on upper limb function in chronic stroke patients: a TMS study. J Neurol Sci 2007;252:76-82.
Tino D, Hillis C. The full can exercise as the recommended exercise for strengthening the supraspinatus while minimizing impingement. Strength Cond J 2010;32:33-35.

van Dulmen AM, Fennis JF, Mokkink HG, van der Velden HG, Bleijenberg

G. Persisting improvement in complaint-related cognitions initiated during medical consultations in functional abdominal complaints. Psychol Med 1997;27:725-729.

Van Gelein Vitringa VM, Jaspers R, Mullender M, Ouwerkerk WJ, Van Der Sluijs JA. Early effects of muscle atrophy on shoulder joint development in infants with unilateral birth brachial plexus injury. Dev Med Child Neurol 2011;53:173-178.

Verbrugghe J, Agten A, Eijnde BO, Vandenabeele F, De Baets L, Huybrechts $X$, Timmermans A. Reliability and agreement of isometric functional trunk and isolated lumbar strength assessment in healthy persons and persons with chronic nonspecific low back pain. Phys Ther Sport 2019; 38:1-7.

Vikne J, Oedegaard A, Laerum E, Ihlebaek C, Kirkesola G. A randomized study of new sling exercise treatment vs traditional physiotherapy for patients with chronic whiplash-associated disorders with unsettled compensation claims. J Rehabil Med 2007;39:252-259.

Willems TM, Witvrouw E, Delbaere K, Mahieu N, De Bourdeaudhuij I, De Clercq D. Intrinsic risk factors for inversion ankle sprains in male subjects: a prospective study. Am J Sports Med 2005;33:415-423.

Wilson T. The measurement of patellar alignment in patellofemoral pain syndrome: are we confusing assumptions with evidence? J Orthop Sports Phys Ther 2007;37:330-341.

Xu W, Zhang X, Zhu Y, Zhu X, Li Z, Li D, Jia J, Chen L, Wang S, Bai Y, Li M. An analysis of clinical risk factors for adolescent scoliosis caused by spinal cord abnormalities in China: proposal for a selective wholespine MRI examination scheme. BMC Musculoskelet Disord 2020;21: 187. 